\title{
QUEEN'S
UNIVERSITY
BELFAST
}

\section{Building global development strategies for cf therapeutics during a transitional cftr modulator era}

Mayer-Hamblett, N., van Koningsbruggen-Rietschel, S., Nichols, D. P., VanDevanter, D. R., Davies, J. C., Lee, T., Durmowicz, A. G., Ratjen, F., Konstan, M. W., Pearson, K., Bell, S. C., Clancy, J. P., Taylor-Cousar, J. L., De Boeck, K., Donaldson, S. H., Downey, D. G., Flume, P. A., Drevinek, P., Goss, C. H., ... Retsch-Bogart, G. Z. (2020). Building global development strategies for cf therapeutics during a transitional cftr modulator era. Journal of Cystic Fibrosis, 19(5), 677-687. https://doi.org/10.1016/j.jcf.2020.05.011

Published in:

Journal of Cystic Fibrosis

Document Version:

Peer reviewed version

Queen's University Belfast - Research Portal:

Link to publication record in Queen's University Belfast Research Portal

\section{Publisher rights}

Copyright 2020 Elsevier

This manuscript is distributed under a Creative Commons Attribution-NonCommercial-NoDerivs License

(https://creativecommons.org/licenses/by-nc-nd/4.0/), which permits distribution and reproduction for non-commercial purposes, provided the author and source are cited

\section{General rights}

Copyright for the publications made accessible via the Queen's University Belfast Research Portal is retained by the author(s) and / or other copyright owners and it is a condition of accessing these publications that users recognise and abide by the legal requirements associated with these rights.

Take down policy

The Research Portal is Queen's institutional repository that provides access to Queen's research output. Every effort has been made to ensure that content in the Research Portal does not infringe any person's rights, or applicable UK laws. If you discover content in the Research Portal that you believe breaches copyright or violates any law, please contact openaccess@qub.ac.uk. 


\section{BUILDING GLOBAL DEVELOPMENT STRATEGIES FOR CF THERAPEUTICS DURING A TRANSITIONAL CFTR MODULATOR ERA}

Mayer-Hamblett $\mathrm{N}^{1.2}$, van Koningsbruggen-Rietschel $\mathrm{S}^{3,4}$, Nichols DP ${ }^{1.2}$, VanDevanter $\mathrm{DR}^{5}$, Davies JC $\mathrm{C}^{6,7}$, Lee $\mathrm{T}^{8}$, Durmowicz $\mathrm{AG}^{9}$, Ratjen $\mathrm{F}^{10}$, Konstan $\mathrm{MW}^{5,11}$, Pearson $\mathrm{K}^{2}$, Bell SC${ }^{12}$, Clancy JP9 , Taylor-Cousar $\mathrm{JL}^{13}$, De Boeck $\mathrm{K}^{14}$, Donaldson $\mathrm{SH}^{15}$, Downey DG ${ }^{16}$, Flume $\mathrm{PA}^{17}$, Drevinek $\mathrm{P}^{18}$, Goss $\mathrm{CH}^{1.2}$, Fajac $\mathrm{I}^{19}$, Magaret $\mathrm{AS}^{1.2}$, Quon $\mathrm{BS}^{20}$, Singleton $\mathrm{SM}^{9}$, VanDalfsen $\mathrm{JM}^{2}$, Retsch-Bogart $\mathrm{GZ}^{15}$

${ }^{1}$ University of Washington, Seattle, WA, ${ }^{2}$ Seattle Children's Hospital, Seattle, WA, ${ }^{3}$ Cystic Fibrosis Center, Children's Hospital, University of Cologne, ${ }^{4}$ Faculty of Medicine and University Hospital Cologne, Cologne Germany, ${ }^{5}$ Case Western Reserve University School of Medicine, Cleveland, OH, ${ }^{6}$ National Heart \& Lung Institute, Imperial College London, London, UK, ${ }^{7}$ Royal Brompton \& Harefield NHS Foundation Trust, London, UK, ${ }^{8}$ Leeds Regional Paediatric Cystic Fibrosis Centre, Leeds, UK, ${ }^{9}$ Cystic Fibrosis Foundation, Bethesda, MD, ${ }^{10}$ University of Toronto, Toronto, Canada, ${ }^{11}$ Rainbow Babies and Children's Hospital, Cleveland, $\mathrm{OH},{ }^{12}$ Children's Health Research Centre, The University of Queensland, Brisbane, Australia, ${ }^{13}$ National Jewish Health, Denver, CO, ${ }^{14}$ University of Leuven, Leuven, Belgium, ${ }^{15}$ University of North Carolina at Chapel Hill, Chapel Hill, NC, ${ }^{16}$ Centre for Experimental Medicine, Queen's University Belfast, Belfast, Northern Ireland, ${ }^{17}$ Medical University of South Carolina, Charleston, SC ${ }^{18}$ Charles University, Prague, Czechia, Motol University Hospital, Prague, Czechia, ${ }^{19}$ Université de Paris, Paris, France, ${ }^{20}$ University of British Columbia, Vancouver, British Columbia

Corresponding Author: Nicole Mayer-Hamblett, PhD

Seattle Children's Hospital

PO Box 5371, M/S CW8-5B

Seattle, WA 98145-5005

nicole.hamblett@seattlechildrens.org

Key Words: Drug development, clinical trials, CFTR modulators, global perspective

Word Count: 5366

Author Contributions: All authors drafted the manuscript or revised it critically for important intellectual content. All authors approved the final version of the manuscript. 
Funding Source: NMH was supported by the Cystic Fibrosis Foundation and National Institutes of Health (NIH) grants P30 DK 089507 and UL1 TR002319. MWK was supported by the Cystic Fibrosis Foundation and NIH grants P01HL128192 and UL1TR002548. JCD was supported by the National Institute for Health Research (NIHR) Clinical Research Facility, Royal Brompton Hospital and NIHR Imperial Biomedical Research Center (BRC). SCB was supported by Australian National Health and Medical Research Council, CF Foundation and Children's Hospital Foundation. PF was supported by the South Carolina Clinical Translational Research (SCTR) Institute, with an academic home at the Medical University of South Carolina, through NIH grant number UL1TR000062. 


\begin{abstract}
As CFTR modulator therapy transforms the landscape of cystic fibrosis (CF) care, its lack of uniform access across the globe combined with the shift towards a new standard of care creates unique challenges for the development of future CF therapies. The advancement of a full and promising CF therapeutics pipeline remains a necessary priority to ensure maximal clinical benefits for all people with CF. It is through collaboration across the global CF community that we can optimize the evaluation and approval process of new therapies. To this end, we must identify areas for which harmonization is lacking and for which efficiencies can be gained to promote ethical, feasible, and credible study designs amidst the changing CF care landscape. This article summarizes the counsel from core advisors across multiple international regions and clinical trial networks, developed during a one-day workshop in October 2019. The goal of the workshop was to identify, in consideration of the highly transitional era of CFTR modulator availability, the drug development areas for which global alignment is currently uncertain, and paths forward that will enable advancement of CF therapeutic development.
\end{abstract}




\section{Introduction}

The cystic fibrosis (CF) community is experiencing transformative changes that will forever alter the landscape of care with the discovery and confirmation of clinically effective CF transmembrane conductance regulator (CFTR) modulator therapies potentially effective for approximately $90 \%$ of the CF population (1). Although tremendously promising, critical goals remain to identify disease modifying therapies for all, develop new therapeutics to address the remaining complications of a multifaceted disease and, equally as important, ensure the equitable access of these therapies to all individuals with CF worldwide. The CF therapeutics pipeline must remain strong now and in the future for these reasons, yet development strategies must accommodate a transitional era in which global access to modulator therapy is variable and dynamic.

Successful development of CF therapies, including both disease modifying therapies and those targeting disease sequelae, will require global development pathways to secure necessary patient populations for satisfaction of regulatory requirements across continents. Questions now arise regarding the willingness of individuals to participate in clinical trials and how this might be impacted by modulator access, in addition to how therapeutic efficacy can be established across a heterogeneous population with this access. In parallel, experience suggests that we will face the ongoing challenge of designing studies to satisfy requirements for both marketing and reimbursement approval - requirements that vary across regulatory agencies globally. As of 2019, three clinical trial networks, including the CF Therapeutics Development Network (CF TDN), the European Cystic Fibrosis Society Clinical Trials Network (ECFS-CTN), and the CF Canada Accelerating Clinical Trials Network (CanACT) have harmonized their scientific protocol review processes for industry sponsors pursuing global development across these regions. This cooperative process offers one pathway for increased consultation with industry during the protocol development phase and prior to regulatory submission to ensure that protocols are acceptable to the CF community in this new era.

Although the advancement of the CF therapeutic pipeline remains an important goal in the highly transitional era of modulator availability (Figure 1), cohesive global development strategies will need to satisfy multiple regulatory agencies while reducing duplicative efforts and overall burden on the CF population. To address these strategies, a group of clinical trial experts across multiple regions (United States, Europe, Canada, Australia) and representative leadership from clinical trial networks (CF TDN, ECFS-CTN, and CanACT) gathered for a one-day workshop in October 2019 in conjunction with the North American CF meetings to identify the key drug development areas across select classes of CF chronic 
therapies for which global alignment is currently uncertain, and to identify paths forward to progress therapeutic development. This work builds upon several ongoing and prior efforts of individual CF trial networks to advance the pipeline of new CF therapies (2-4). This paper outlines the key content discussed in this workshop with an executive summary provided in Table 1.

Table 1. Executive Summary of the Workshop to Support Global CF Therapeutic Development

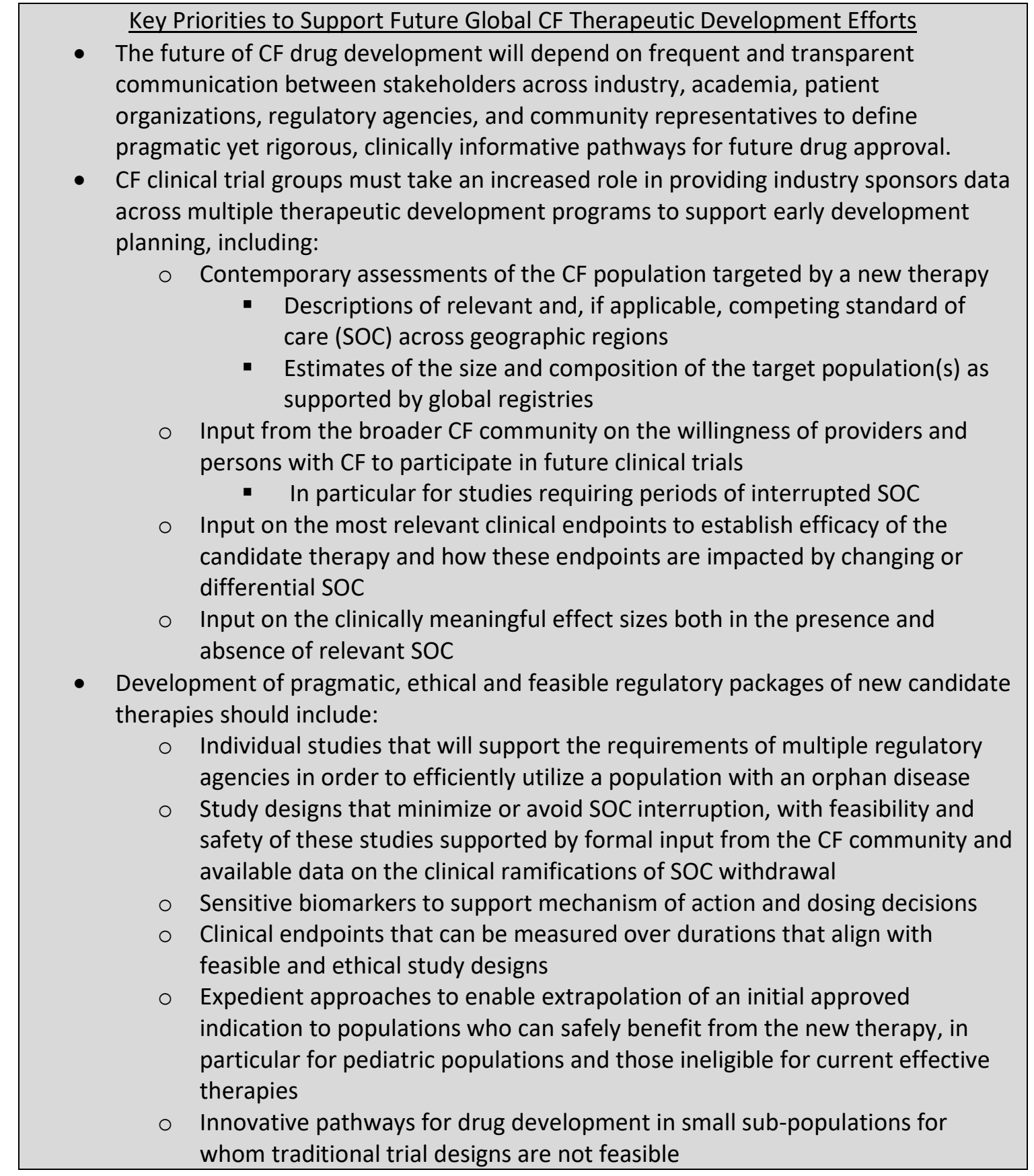




\section{Paving the Way for the Development of New CFTR Modulators}

Just over a decade has passed from the initial clinical trials of ivacaftor, the first CFTR modulator monotherapy associated with substantial clinical benefit, to the recent Food and Drug Administration (FDA) approval of the CFTR modulator combination elexacaftor/tezacaftor/ivacaftor, also associated with substantial clinical benefit, for persons with CF with at least one F508del mutation. Approvals of other CFTR modulators, including lumacaftor/ivacaftor and tezacaftor/ivacaftor are on average associated with more modest clinical benefit in clinical trials(5), although individual responsiveness is variable across all modulator therapies. This recent milestone of the approval of elexacaftor/tezacaftor/ivacaftor is a critical one for the CF community, which could declare modulator development "completed" for eligible individuals or instead motivate continued development of additional modulators now that "proof of concept" for CFTR modulation has been definitively established. Without hesitation, the latter path has been strongly endorsed by the community for a multitude of reasons, including heterogeneity of individual response to current modulator therapy, lack of long-term safety data consistent with chronic lifetime use, and lack of global access related to high costs for public and private payers. Several early to mid-phase novel CFTR modulator development programs are currently underway (Figure 1). These programs face an unprecedented situation: the development of a novel, competing therapy with a highly effective standard of care alternative indicated for up to $90 \%$ of the CF population. Thus, as these development programs mature, this reality creates an opportunity to re-define and inform innovative, pragmatic, and ethical approval pathways.

\subsection{Regulatory Approval Pathways for Novel Compounds Targeting Mutations Already Eligible for CFTR Modulator Therapy Associated with Substantial Clinical Benefit}

When the target study population for a new modulator includes individuals with mutations already eligible for commercially approved modulators associated with substantial clinical benefit (including ivacaftor and elexacaftor/tezacaftor/ivacaftor), industry sponsors must decide whether to pursue development in those (a) indicated for approved modulators but who lack access, (b) with access to approved modulators, or (c) a combination of the two. In the case of (a), the population size is dynamic and lessening over time, and thus would most feasibly support early rather than late phase 
development efforts. Further, ethical considerations arise when proposing early phase studies in populations who may face challenges gaining access to the new treatment after approval. Lack of access to current effective therapies could render these populations particularly vulnerable: eager to test new therapies that may not yet offer prospect of benefit in early phase development coupled with uncertain access to these therapies if approved. On the other hand, in the case of (b), strong ethical concerns arise when asking individuals to forgo treatment associated with substantial clinical benefit that is potentially life-extending for more than a brief period of time to assess the effectiveness of a new therapy that may have similar or even inferior effects. Sponsors will need to assess the willingness of this particular population to participate in such clinical trials and work with regulators to reduce the time interval of discontinuing effective treatments to the minimum required to understand the efficacy of the new treatment. Sponsors wanting or needing to study their drugs in both populations will likely require multiple trial designs, and ethical concerns for both populations will remain. However, it is highly likely that the later phase development of any future candidate modulator will necessitate the enrollment of participants who have already been chronically treated with CFTR modulators due to the growing size of this population and requirements for generalizability of study results.

A global development strategy should account for the differential preferences of regional regulatory agencies on key study design parameters such as choice of comparator (active or placebo), duration and primary endpoint, as overviewed in Table 2 for two example regulatory agencies, the FDA and the European Medical Agency (EMA). Historically, differential requirements have necessitated the development of two distinctively different pivotal trial designs such as the case in anti-infectives (Table 2). Ideally, a new precedent will allow for a development strategy utilizing studies that will satisfy multiple regulatory agencies, in parallel exercising flexibility in the pathway required to establish substantial evidence of efficacy as described in recent regulatory guidance(6). For the development of a new candidate modulator, a few viable (and likely feasible) pivotal study designs should be considered for subjects with current access to CFTR modulators associated with substantial clinical benefit including and most notably elexacaftor/tezacaftor/ivacaftor. In isolation, these designs admittedly fall short of the precedent set by prior six-month placebo-controlled trials evaluating both percent predicted forced expiratory volume in 1 second $\left(\mathrm{ppFEV}_{1}\right)$ and pulmonary exacerbation endpoints for efficacy. However, in combination, they could constitute an adequate and robust application to regulators supporting both the short- and long-term efficacy and safety of a new candidate CFTR modulator (Table 3). Examples of studies contributing to such a pragmatically-focused application include: 
(1) Short-term placebo-controlled trial followed by an open label (and expanded) long term safety study. Willingness of persons with access to CFTR modulator therapy to participate in a placebocontrolled trial has been explored on a limited basis in individuals with CF taking ivacaftor, demonstrating a threshold for participation that favored studies one month or less(7). A recent trial of an early phase compound, GLPG1837 (a candidate CFTR potentiator) in G551D CF patients, predominantly enrolled those on chronic ivacaftor and included an approximately seven-day withdrawal period prior to initiation of the candidate therapy(8). This trial demonstrated feasible enrollment but an average $5 \%$ decline in $\mathrm{ppFEV}_{1}$ over this brief withdrawal period, recoverable after administration of the candidate therapy. Limited data are available on the safety of longer-term withdrawal of CFTR modulator therapy but are expected to be available in the ongoing 16 -week trial of a potentiator compound VX-561 among those withdrawing ivacaftor (NCT03911713). The ultimate feasibility of future placebo-controlled trials, similar in nature to randomized withdrawal studies in this setting, will depend on more contemporary CF community input on the willingness to be randomized to placebo after elexacaftor/tezacaftor/ivacaftor, in addition to the accumulating safety data on the clinical impact of withdrawal. If feasible in a population with access to CFTR modulators associated with substantial clinical benefit, a short placebo-controlled trial can only rely on proximal efficacy endpoints such as pulmonary function and sweat chloride, necessitating additional studies to support the sustainability of short-term efficacy and longer-term safety. Participants in this short placebo-controlled trial would transition into a larger and longer term open-label safety study (Table 3), as the sample sizes required for the trial to establish efficacy would be relatively small $(<120)$ - an advantage for minimizing the number of subjects exposed to placebo(4).

(2) Active-comparator trial. A logical alternative to a placebo-controlled trial in populations with access to modulators is an active-comparator trial, although this design would be pragmatically modified for the setting of CFTR modulators. The active comparator tested against a candidate treatment would be the commercially approved standard of care modulator treatment; however, acquisition and blinding of the comparator (which would necessitate a modification of the commercial packaging and delivery) would be prohibitive for most sponsors from both a financial and legal perspective. It is likely that such an approach could only be realized by relying on prescription-based access to comparator therapy. Importantly, this would result in an openlabel, unblinded design which may be problematic for regulators. Further, participants in both treatment arms would presumably have access to the active comparator as eligibility for the 
study would require ability to acquire this therapy through a prescription, promoting additional challenges to study design and potential confounding. Subjects who know they are receiving the new candidate test therapy could question its efficacy and choose to re-start their prescribed, known effective therapy at any time. These issues cannot be avoided but can be mitigated through careful education and limiting the duration of the study, as well as prioritizing objectively measured clinical endpoints and biomarkers including lung function and sweat chloride. Lastly, the candidate modulator will likely be hypothesized to be non-inferior to the active comparator, necessitating justification of a non-inferiority margin. Importantly, this margin has considerable flexibility in the context of a highly effective active comparator therapy when assessing total clinical benefit of the candidate therapy (Table 2). Subjects in this study would have the opportunity to participate in the long-term open label safety study for evaluation of sustained benefit in addition to safety.

(3) Historical control group versus an active comparator. Within the rare disease setting, particularly when it is unethical to randomize participants to placebo, the use of historical controls in lieu of a placebo control has been used sparingly for regulatory approval with a key example provided in the setting of Pompe disease(9). The pooled data across the open label study arms noted above represents a tremendous opportunity to create a larger and longer active comparator arm that can be compared to a matched historical control group to derive long-term efficacy estimates on standardized clinical outcomes. Data both from patient registries and recently completed clinical trials provide potentially rich sources for the derivation of historical controls. Methodologic work is currently underway to articulate when this approach is appropriate and to assess approaches for bias minimization $(10,11)$, both of which are necessary components to support the use of historical controls in future regulatory packages.

Importantly, these study designs do not constitute the only feasible and ethically acceptable options for the development of a new therapy from an existing effective modulator class. Rather, they are intended to illuminate via Table 3 a new potential paradigm for future discussion with regulators that is intended to satisfy multiple regulatory agencies and replace a more traditional longer duration, two pivotal confirmatory trials framework that appears to no longer be feasible. In parallel, equal attention must be directed towards the integration of endpoints and design elements into these regulatory-driven trials (when feasible) to create an efficient framework for health technology assessments (HTAs) which are necessary for providing regional access to new therapies once regulatory approval has been established. 


\subsection{Extrapolation Beyond the First Approval}

Extrapolation of an initial approved indication to a broader patient population remains a complex issue with differing regulatory approaches. With respect to CFTR modulators, of primary interest is the extent to which safety and efficacy data from trials in initially pursued indications can be extrapolated to younger patient populations (discussed in Section 4) and to those with rare mutations. In particular, the FDA has established precedent and new regulatory guidance with the expansion of the ivacaftor label to include additional rare mutations based on in vitro assay data demonstrating increased chloride ion transport across cells in response to ivacaftor(12). This pragmatic approach has not been uniformly adopted across all regulatory agencies, for example as evidenced by varying requirements to provide clinical efficacy data in additional mutations under consideration for expansion of the ivacaftor label. Obtaining this clinical efficacy data is not without difficulty and while approaches such as n-of- 1 designs can be considered, the data from these studies must be cautiously interpreted(13). In critical efforts to expand indications of approved therapies to broader populations who may benefit(2,14, 15), previous reviews describe approaches to identify the optimal methodology upon which extrapolation should be based and proposed strategy for expanding the use of extrapolation(2, 14, 15).

\subsection{Novel Compounds Targeting Rare Mutations}

Despite a therapeutics pipeline offering prospect of disease modifying therapies for the remaining 10$15 \%$ of the CF population ineligible for CFTR modulator therapy (Figure 1), there is currently no example pathway for the approval of a new, disease-modifying, first-in-class therapy for populations with rare mutations. There are approximately 1000 CFTR variants known to cause disease, but with fewer than five individuals with the mutation globally(14); non-traditional trial designs and new criteria for efficacy data sufficient for approval will be necessary to bring therapies to those with rare mutations. A new and novel regulatory pathway has been proposed as part of a European HORIZON2020 project in collaboration with the European Cystic Fibrosis Society Clinical Trials Network (ECFS-CTN) which begins by predicting benefit of a candidate modulator drug at an individual level using one of multiple preclinical model systems. Depending on their response, individuals with rare CFTR mutations exceeding an a priori response to candidate modulators tested using their own biological materials could then progress to an n-of-1 trial, a basket trial or be granted early access to CFTR modulator treatment(14). This pathway not only offers a potential path for regulatory approval for specific mutations, but also represents a precision-based therapy approach towards personalized CF medicine. This approach is 
already underway through the HIT-CF research project in Europe (https://www.hitcf.org/) which has garnered support and participation from several industry sponsors.

\section{Ensuring and Advancing the Development of New Symptomatic Therapies}

CF drug development challenges differ for CFTR modulators compared to those therapeutic classes that target "downstream consequences" of CFTR dysfunction, including airway obstruction, infection, and inflammation (collectively referred to here as "symptomatic" therapies). Previously, CF drug development guidance from two influential regulatory agencies, the FDA and EMA, has lacked harmonization and alignment on trial and data requirements for product registration for symptomatic therapies (Table 2). The precedent set by past inhaled antimicrobial development programs, for which multiple pivotal trial designs were executed by sponsors to meet preferences of different regulatory agencies, may no longer be a viable approach as CFTR modulator therapy and more effective symptomatic therapies are adopted as standards of care. Although there is anticipation that modulator initiation in infancy will delay or inhibit progression to complications targeted by symptomatic therapies, for individuals with CF who already have or will develop bronchiectasis, chronic airway infection, and inflammation, the need for new and more effective symptomatic CF therapies will remain. In an era where regional diversity of access to effective therapies will exist, sponsors and regulators will need to consider the ethics of trial designs that withhold available effective treatments from study subjects and/or study populations with little hope of access to effective treatments after approval. As a result, regulators may be more amenable towards greater biomarker use for assessment of efficacy and active (unblinded) comparator designs to meet data preferences across regulatory agencies (Table 2).

Future symptomatic CF therapy development efforts will likely be influenced by regional differences in CFTR modulator availability: CF populations without access will have the greatest medical need for these therapies and thus their study in these populations will be essential. However, sponsors will need and want to demonstrate that their new therapies are also effective as CFTR modulator adjuncts in anticipation of increased global access. Two of the more challenging development areas are in the setting of anti-infectives and anti-inflammatories and were prioritized for discussion in the workshop. While the development of mucolytics are equally as important, the development strategy for these therapies - which relies on placebo-controlled trials and pulmonary function endpoints to establish 
clinical efficacy - is likely to remain relatively consistent even during a changing landscape of standard of care therapy.

\subsection{Anti-infective Therapies for Chronic Airway Infection}

Chronic airway infection is a hallmark disease manifestation of CF, representing a key therapeutic target. Both scientific discovery and drug development have often focused on a relatively small number of "keystone" pathogens, but less common pathogens and a more complex microbiota are increasingly appreciated. Drug development efforts are perhaps most matured for $P$. aeruginosa, which is closely linked with clinical decline and for which drug development has been most successful to date(16-20). This success has resulted in multiple therapeutic options for the treatment of chronic $P$. aeruginosa, and subsequently prompts a great need to adapt the development approach for future candidate therapies competing with a complex landscape of standard of care.

Regional differences in current standard of care. Inhaled antibiotics are a recognized standard of care around the world, but regional availability and preferences for specific drugs differ(21, 22). Some are used continuously while others are cycled on and off, typically every 4 weeks. Increasingly, two inhaled drugs are cycled in a continuous fashion to avoid periods without antibiotic use (i.e. continuous alternating therapy [CAT]). Such differences in preferred antibiotics and patterns of administration have important implications when considering where and how to test new candidate therapies, particularly as the efficacy of evolving standard of care has not been quantified in prospective trials(23). A single, efficient drug development plan that applies to the diverse, global CF population while satisfying multiple regulatory agencies is a worthy ideal. For inhaled antibiotics, this proposed approach is challenging and will require skillful planning with sponsors, regulatory agencies, and those conducting or participating in trials.

Anticipated impact of CFTR modulator therapy. Increasing yet variable access to CFTR modulator therapy associated with substantial clinical efficacy also complicates antimicrobial drug development. These drugs, while not directly antimicrobial, clearly alter the airway environment and have overlapping effects on key outcome measures(24-27). Sustained improvement in $\mathrm{ppFEV}_{1}$ has generally been the primary outcome measure for clinical trials of inhaled antibiotics and is often supported by additional data showing a reduced risk of acute pulmonary exacerbation or reduced respiratory symptoms. Elexacaftor/tezacaftor/ivacaftor most recently has been shown to dramatically improve ppFEV $\mathrm{V}_{1}$ while reducing respiratory symptoms and the risk of exacerbation $(28,29)$. Programs developing new 
antimicrobial therapies must anticipate these and other changes in clinical standards that may impact their trials. In study populations using elexacaftor/tezacaftor/ivacaftor for instance, demonstrating further reduction in the rate of pulmonary exacerbation may be difficult, and it is unclear how well inhaled antibiotics may perform in assessment of respiratory symptoms or even lung function when tested in modulator-treated populations. Spontaneous sputum expectoration is often more difficult after initiation of CFTR modulators deemed more highly effective clinically and mechanistically, making demonstration of antimicrobial effects an additional challenge(30). Induction procedures will likely be necessary, and research to develop alternative methods to reliably measure airway infection in all age groups, either qualitatively or quantitatively, should be prioritized. As transformative therapies emerge and global access improves, morbidity will decline, and greater priority may be placed on perceived burden or complexity of daily care(31). While uncertain, it is believed that patients may prioritize characteristics such as dosing frequency, portability, storage requirements, and administration time.

Study design considerations. Similar to other therapeutic classes, recruiting to antimicrobial trials with lengthy placebo-controlled periods will be difficult. For many, available clinical care options for inhaled antibiotics have reduced or eliminated the antibiotic-free cycled periods available in the past to test new antimicrobial drugs(3). Even with CFTR modulators as established standard of care, relatively few individuals with CF or their care providers may be comfortable reducing from continuous inhaled antibiotics or continuous alternating therapy in those who remain infected with $P$. aeruginosa. It is conceivable to add new antibiotics on top of existing drugs, but this may lead to complicated, burdensome trial requirements that will not appeal to those considering overall treatment burden. Table 2 outlines some alternative approaches to antimicrobial study design that may be feasible and informative. Alternatives to previously used, large-scale designs must be considered if new therapies are to be developed, and a combination of studies may be needed to provide an acceptable level of evidence (Table 3).

There is also an important role for advancing outcome measures. For antimicrobial drugs in particular, the utility of multiple breath washout/lung clearance index (LCI) as an outcome measure in such studies is poorly understood but deserves focused study $(32,33)$. Revised definitions for pulmonary exacerbation and ways to measure quality of life gains in a healthier population are also neededparticularly for larger pivotal trials(34). CF clinicians and investigators generally agree that these trials should include substantial numbers of participants who reflect the intended patient population for drug marketing and clinical use. It is critical to consider the needs of those without access to CFTR modulators 
and ensure that they are included in antimicrobial drug development plans. Such populations may have the most to gain from symptomatic therapies, and sensitive outcome measures that are effective in modulator-treated groups for detecting treatment effects are likely to also work in those awaiting access to these modulators.

\subsection{Anti-inflammatory Therapies}

CF is characterized by dysregulated airway inflammation with both exaggerated innate response and defective downregulation once initiated(35). Inflammation directly damages the airways primarily through the action of proteases, leading to bronchiectasis and progressive loss of lung function, which is the most common cause of premature death in individuals with $\mathrm{CF}(36)$. For this reason, targeting lung inflammation has long been recognized as a potentially beneficial CF management strategy(37). It has been more than twenty five years since long-term placebo-controlled trials of prednisone(35) and ibuprofen $(38,39)$ were begun, yet despite both drugs demonstrating proof of concept evidence of benefit on lung function, and more recently evidence for a survival benefit with ibuprofen(40), no antiinflammatory therapy for CF has gained regulatory approval (Table 2). Industry sponsors interested in anti-inflammatories for CF face many challenges regarding suitable drug candidates, biomarkers, and study design issues related to efficacy endpoints(41).

Host inflammatory pathways are quite extensive and redundant, choosing where to act in the pathways, and choosing either a broad-spectrum or targeted agent, has proven difficult. Unlike infection in the CF lung, where eliminating the burden of bacteria is the goal, some inflammation is required, just not too much. A planned 600 patient international trial of an LTB4 receptor antagonist was stopped early due to pulmonary-related serious adverse events in the active arm(37), presumably related to over-suppressing inflammation. It is easy to state that sponsors should employ biomarkers of inflammation in early phase studies to obtain evidence that their drug candidate reduces inflammation, sufficiently but not excessively. Unfortunately, the identification of many candidate inflammatory biomarkers (42) has not elucidated the magnitude of biomarker change that may be associated with "clinically meaningful" treatment effects.

Mechanistic and operational arguments can be made for use of free neutrophil elastase concentration in induced or expectorated sputum as a primary biomarker of lung inflammation, as higher levels are associated with a greater subsequent lung function decline as well as with the development of bronchiectasis (43-46). Importantly, this relationship remains associative, without proven causality. 
Further, treatment-associated reduction of CF airway inflammation should also be accompanied by consistent (directional) changes across more than one inflammatory biomarker. Movement of any single biomarker without changes in others should probably be viewed with skepticism. Furthermore, as noted above in the era of new and more effective CFTR modulators, spontaneously produced and even induced sputum may be more difficult to acquire for measurement of sputum biomarkers of inflammation as early phase trial endpoints.

A limited number of clinical endpoints have been employed to demonstrate efficacy of chronic CF respiratory therapies: primarily improvements in $\mathrm{FEV}_{1}$, weight, and quality of life and reduction in the rate or risk of pulmonary exacerbation (47). Most pivotal trials of approved CF drugs have not exceeded six months duration. During the design of the early prednisone and ibuprofen trials, four-year study durations were chosen to assess change in lung function over an extended time period, in part because an acute improvement in $\mathrm{FEV}_{1}$ was not expected to occur with anti-inflammatory therapy, and also because studies employing rate of $\mathrm{FEV}_{1}$ decline as an efficacy endpoint require at least 18-month duration to detect differences in decline rate change, regardless of sample size(48). Although slowing $\mathrm{FEV}_{1}$ decline is predictive of long-term survival in $\mathrm{CF}$ and may be a more meaningful endpoint than sustained $\mathrm{FEV}_{1}$ improvement, studies with durations exceeding a year are impractical in an era of everexpanding therapies in CF. Demonstration of exacerbation rate or risk change also require longer trial durations than for sustained $\mathrm{FEV}_{1}$ improvement, but still less than those of $\mathrm{FEV}_{1}$ decline trials, and appear favored by current drug developers of anti-inflammatory drugs for CF (Table 2). Lack of a nearterm clinical endpoint increases the importance of inflammatory biomarkers as endpoints in earlier clinical trials, although there is also some question as to whether observation of meaningful inflammatory biomarker changes also requires extended observation periods(49).

As noted in previous sections, increasing CFTR modulator access will affect future anti-inflammatory therapeutic development. To the extent that populations with modulator access experience reduced rates of lung function decline, exacerbation risk and incidence, together with improved quality of life (50), anti-inflammatory trials employing these efficacy endpoints in modulator-treated populations will require larger sample sizes and/or longer durations to demonstrate efficacy.

\section{Considerations for Pursuing Development in Pediatric Populations}

Pediatric drug development for an orphan disease requires global cooperation. Achieving this goal depends on alignment between regulatory agencies and sponsors with regard to pediatric development 
plans which outline pharmacokinetic, safety and efficacy outcomes. Pediatric drug development has complexities beyond those of adult programs, based on the additional regulatory and ethical requirements for pediatric programs. For example, in the United States (US), because children are considered a vulnerable population, in order to conduct research in pediatric patients, the study must not involve greater than minimal risk or, alternatively, offer the prospect of direct benefit (51). Additionally, once benefit has been definitively established, typically based on data in adults with the same condition, efficacy may be extrapolated (52). The EMA has not relied on extrapolation in the same way, and generally requires an assessment of efficacy in pediatric studies. Safety may not be extrapolated under either FDA or EMA regulations.

For drugs intended to treat a disease or condition that exists in the pediatric population, the FDA and EMA each require the sponsor to submit a pediatric development plan while the development program in the adult population is ongoing, however with unique differences (Table 4). For an orphan indication such as CF, the FDA requirement for conducting studies in the pediatric population is waived. Nevertheless, sponsors may have incentives, e.g., extended market exclusivity, to conduct pediatric studies but there is no specific mandated timeframe(53). On the other hand, the EMA requires a sponsor to submit a binding Pediatric Investigational Plan (PIP) at the end of phase 1, but amendments can be made through phases 2 and 3 based on the availability of new data and clinical trial experience. The differences in timing of proposal and review of pediatric studies across regulatory agencies can thus pose a challenge when developing a global program $(54,55)$. Communication between regulatory agencies around pediatric drug development issues exists through monthly discussions among the US, European, Japanese, Canadian, and Australian regulatory authorities although common review of global pediatric study plans is not mandated. It is unclear if these discussions have the potential to improve timing and alignment around pediatric plans so that study protocols can meet all the necessary goals. Coordination of the plans would facilitate timely study completion in an ethical fashion with the ultimate goal of providing safe and efficacious therapy to children with CF.

Although efficacy endpoints may not always be required by the FDA for pediatric approval (Table 4), specific efficacy assessments may be important to consider since the natural history of CF affects some organ systems differently early in life and highly effective therapies may hold the potential for prevention or reversibility of the loss of function, an example being restoration of pancreatic exocrine function with ivacaftor $(56,57)$. Beyond the requirements for efficacy data by the EMA, specific efficacy assessments may be of substantial value in a Health Technology Assessment (HTA) to secure funding 
from healthcare systems after approval. Pulmonary efficacy measures are challenging in this age group as children may not be able to perform spirometry reliably and many of those who can have values in the normal range. $\mathrm{LCl}$ derived from non-effort-dependent multiple breath washout has been standardized across trials networks(58), and confirmed as both feasible and sensitive as a trial outcome measure in younger age groups $(58,59)$. As the pulmonary health of the CF population in general improves on CFTR modulators, $\mathrm{LCl}$ may be an outcome measure with utility across a broader age range.

Pediatric study designs will largely depend on the requirements to establish safety only or both efficacy and safety. Placebo-controlled trials may be desirable not only to establish efficacy but, in some cases, to determine whether safety signals or improvements in organ dysfunction are related to the underlying disease process or related to adverse or beneficial effects of the investigational agent. However, when the standard of care has established the use of a specific class of therapy, stopping such therapy in the pediatric age group may not be ethical, unlike the case for adults who are able to assess the potential risk of being allocated to placebo given sufficient information.

Once a therapy has been adopted into standard of care, the importance of long-term safety monitoring is heightened in pediatric populations who may need a highly effective therapy throughout their lifetime spanning developmental periods (such as those related to growth, organ development and puberty) which are not relevant for adults. The responsibility and structure/organization for how this monitoring is accomplished is not clear at this time but may be fulfilled through efforts to enhance global registries poised to capture longitudinal outcomes across the CF population.

\section{Conclusion}

While the successes are celebrated with the remarkable discovery and availability of breakthrough CFTR modulator therapy, clearly more work needs to be done. The CF community is committed to supporting the advancement of a full and promising global therapeutics pipeline aimed at addressing the ongoing needs for people with CF. This workshop provided an initial step towards future extended collaborations with sponsors, regulators, and patient organizations in identifying areas for which harmonization is lacking and for which efficiencies can be gained to promote ethical, feasible, and credible study designs amidst the changing landscape of CF care. The ability to promote alignment across national and regional regulatory agencies, and even more to address the challenges for reimbursement of approved but very expensive therapies, is still limited $(1,2)$. Progress in this area will require multiple interventions, such as providing successful examples of and fostering more collaborative work across agencies, along with 
honest discussion about existing barriers and a better understanding of the similarities and differences each region faces to provide access to new therapies.

Conflict of Interest Statement: $\mathrm{NMH}$ serves as a consultant through her institution in her role as Executive Director of the CF Therapeutics Development Network Coordinating Center (CF TDNCC) and has received personal consulting fees from Kala Pharmaceuticals and Calithera. She has received grant funding from the Cystic Fibrosis Foundation (CFF) and National Institutes of Health (NIH). SvKR has received personal consulting fees from Antabio, Proteostasis Therapeutics (PTI), and Vertex Pharmaceuticals (VRTX). She has received grant support to her institution for her participation in the European Union HORIZON 2020 work. DPN serves as a consultant through his institution in his role as Medical Director of CF TDNCC. He has received grant support to his Institution from the CFF and Gilead Sciences. DRV has received personal consulting fees from AbbVie, Albumedix, AN2, Aradigm, Armata, Arrevus, Calithera, Chiesi USA, Cipla, Corbus, CFF, Eloxx, Enbiotix, Eveo, Galephar, Horizon, IBF, ICON clinical sciences, Ionis, Kala, Merck, Microbion, NDA, Protalix, PTC, Pulmocide, Recida, Savara, Vast, and VRTX. JCD has received other support from Aligipharma AS, Bayer AG, BI, Galapagos NV, ImevaX GmbH, Nivalis Therapeutics, ProQR Therapeutics, PTI, Raptor Pharamceuticals, VRTX, Enterprise, Novartis, Pulmocide, Flately and Teva for advisory board and educational activities. She has received grant support from the CF Trust. TL has received personal fees from Alan Boyd Consultants, Ltd for his participation in DSMB activities. FAR has received personal consulting fees from Novartis, Bayer, Roche, and Genentech for participation in CF related consulting activities. He has received grant support to his institution from VRTX for his participation as site PI in multicenter trials which they have funded as well as personal consulting fees. MWK has received personal consulting fees for advisory board participation, grant support to his institution for clinical trial participation, and non-financial support from VRTX, Savara, Laurent, Corbus Pharmaceuticals, PTC, and AzurRx. He has received personal consulting fees and non-financial support from Chiesi, Celtaxsys, Merck, and Kala. Personal consulting fees were received from Albumedix, Paranta, Protalix, Santhera, pH Pharma, Novartis, Ionis, the Italian Cystic Fibrosis Foundation, and the Food and Drug Administration. Grant support was provided to his Institution by $\mathrm{NIH}$. Grant support was provided to his Institution by Anthera as well as personal consulting fees. SCB has received support from VRTX, Galapagos, and AbbVie for his participation in advisory boards and as site PI in multicenter trials which they have funded. JLTC has received personal consulting fees from Gilead Sciences, Protalix, and Santhera for participation in advisory board activities. She has received 
grant support to her institution from PTI, Celtaxsys, and VRTX as well as personal consulting fees for advisory activities. Grant support to her institution for her participation as site PI in a multicenter trial which they have funded from Eloxx. KDB has received consulting fees from Boehringer-Ingelheim (BI), Protalix Biotherapeutics, Raptor Pharmaceuticals, Novabiotics, Eloxx Pharmaceutics, Galapagos, and Chiesi. She has received speaker fees from Teva Pharmaceutical Industries and serves on the Steering Committee and Advisory Board for VRTX. DGD has received consulting fees from VRTX and consulting fees as well as grant support from PTI and Chiesi. PAF has received personal consulting fees from the Food and Drug Administration, Polyphor, and Santhera. He has received personal consulting fees and grant support from CFF, PTI, Savara, and VRTX. He has received grant support from NIH, Novartis, Novoteris, and Sound Pharmaceuticals. PD has received personal consulting fees from VRTX, PTI, and Actelion Pharmaceuticals. He has also received support for his participation as site PI in multicenter trials funded by Corbus Pharmaceuticals and VRTX. CHG has received grant funding from CFF, NIH, the European Commission and the Food and Drug Administration. He has also received honoraria from Gilead Sciences for grant reviews, honoraria from VRTX and Mylan for invited talks, and BI for participation as a PI in a multicenter trial in CF that they have funded. IF has received consulting fees and support from PTI, VRTX and BI for her participation in advisory boards as well as site PI in multicenter trials which they have funded. She has received support from Corbus Pharmaceuticals for participation as site PI in multicenter trials which they have funded ASM has received grant support to her Institution from CFF. BSQ has received grant support to his institution from the Cystic Fibrosis Canada, CFF, Michael Smith Foundation for Health Research, BC Lung Association, and Gilead Sciences. GZRB's institution has received support from the CFF, NIH and VRTX. for his participation as site PI in multicenter trials which they have funded. AGD, KP, JPC, SHD, SMS, and JMVD have nothing to disclose. 


\section{References}

1. Bell SC, Mall MA, Gutierrez H, Macek M, Madge S, Davies JC, Burgel PR, Tullis E, Castanos C, Castellani C, Byrnes CA, Cathcart F, Chotirmall SH, Cosgriff R, Eichler I, Fajac I, Goss CH, Drevinek P, Farrell PM, Gravelle AM, Havermans T, Mayer-Hamblett N, Kashirskaya N, Kerem E, Mathew JL, McKone EF, Naehrlich L, Nasr SZ, Oates GR, O'Neill C, Pypops U, Raraigh KS, Rowe SM, Southern KW, Sivam S, Stephenson AL, Zampoli M, Ratjen F. The future of cystic fibrosis care: a global perspective. Lancet Respir Med 2020; 8: 65-124.

2. Davies JC, Drevinek P, Elborn JS, Kerem E, Lee T, European CFSSPTFoSuatndfCF, Amaral MD, de Boeck K, Davies JC, Drevinek P, Elborn JS, Kerem E, Lee T. Speeding up access to new drugs for CF: Considerations for clinical trial design and delivery. J Cyst Fibros 2019; 18: 677-684.

3. Nichols DP, Durmowicz AG, Field A, Flume PA, VanDevanter DR, Mayer-Hamblett N. Developing Inhaled Antibiotics in Cystic Fibrosis: Current Challenges and Opportunities. Ann Am Thorac Soc 2019; 16: 534-539.

4. Mayer-Hamblett N, Boyle M, VanDevanter D. Advancing clinical development pathways for new CFTR modulators in cystic fibrosis. Thorax 2016; 71: 454-461.

5. Mall MA, Mayer-Hamblett N, Rowe SM. Cystic Fibrosis: Emergence of Highly Effective Targeted Therapeutics and Potential Clinical Implications. Am J Respir Crit Care Med 2019.

6. U.S. Department of Health and Human Services FDA, Center for Biologics Evaluation and Research CBER, Center for Drug Evaluation and Research CDER. Demonstrating Substantial Evidence of Effectiveness for Human Drug and Biological Products, Guidance for Industry; 2019.

7. VanDevanter DR, Mayer-Hamblett N, Boyle M. Feasibility of placebo-controlled trial designs for new CFTR modulator evaluation. J Cyst Fibros 2017; 16: 496-498.

8. Davies JC, Van de Steen O, van Koningsbruggen-Rietschel S, Drevinek P, Derichs N, McKone EF, Kanters D, Allamassey L, Namour F, de Kock H, Conrath K. GLPG1837, a CFTR potentiator, in p.Gly551Asp (G551D)-CF patients: An open-label, single-arm, phase 2a study (SAPHIRA1). J Cyst Fibros 2019; 18: 693-699.

9. Moscicki RA, Tandon PK. Drug-Development Challenges for Small Biopharmaceutical Companies. $N$ Engl J Med 2017; 376: 469-474.

10. Franklin JM, Glynn RJ, Martin D, Schneeweiss S. Evaluating the Use of Nonrandomized Real-World Data Analyses for Regulatory Decision Making. Clin Pharmacol Ther 2019; 105: 867-877.

11. Magaret A, Warden M, Simon N, Heltshe S, Mayer-Hamblett N. Real-world evidence in cystic fibrosis modulator development: Establishing a path forward. J Cyst Fibros 2020.

12. Durmowicz AG, Lim R, Rogers H, Rosebraugh CJ, Chowdhury BA. The U.S. Food and Drug Administration's Experience with Ivacaftor in Cystic Fibrosis. Establishing Efficacy Using In Vitro Data in Lieu of a Clinical Trial. Ann Am Thorac Soc 2018; 15: 1-2.

13. Magaret AS, Mayer-Hamblett N, VanDevanter D. Expanding access to CFTR modulators for rare mutations: The utility of n-of-1 trials. J Cyst Fibros 2019.

14. Amaral MD, de Boeck K, CF ESPTFoSuatndf. Theranostics by testing CFTR modulators in patientderived materials: The current status and a proposal for subjects with rare CFTR mutations. $J$ Cyst Fibros 2019; 18: 685-692.

15. Clancy JP, Cotton CU, Donaldson SH, Solomon GM, VanDevanter DR, Boyle MP, Gentzsch M, Nick JA, Illek B, Wallenburg JC, Sorscher EJ, Amaral MD, Beekman JM, Naren AP, Bridges RJ, Thomas PJ, Cutting G, Rowe S, Durmowicz AG, Mense M, Boeck KD, Skach W, Penland C, Joseloff E, Bihler H, Mahoney J, Borowitz D, Tuggle KL. CFTR modulator theratyping: Current status, gaps and future directions. J Cyst Fibros 2019; 18: 22-34.

16. Ramsey BW, Pepe MS, Quan JM, Otto KL, Montgomery AB, Williams-Warren J, Vasiljev KM, Borowitz $D$, Bowman CM, Marshall BC, Marshall S, Smith AL. Intermittent administration of inhaled 
tobramycin in patients with cystic fibrosis. Cystic Fibrosis Inhaled Tobramycin Study Group. N Engl J Med 1999; 340: 23-30.

17. Konstan MW, Flume PA, Kappler M, Chiron R, Higgins M, Brockhaus F, Zhang J, Angyalosi G, He E, Geller DE. Safety, efficacy and convenience of tobramycin inhalation powder in cystic fibrosis patients: The EAGER trial. J Cyst Fibros 2011; 10: 54-61.

18. McCoy KS, Quittner AL, Oermann CM, Gibson RL, Retsch-Bogart GZ, Montgomery AB. Inhaled aztreonam lysine for chronic airway Pseudomonas aeruginosa in cystic fibrosis. Am J Respir Crit Care Med 2008; 178: 921-928.

19. Schuster A, Haliburn C, Doring G, Goldman MH, Freedom Study G. Safety, efficacy and convenience of colistimethate sodium dry powder for inhalation (Colobreathe DPI) in patients with cystic fibrosis: a randomised study. Thorax 2013; 68: 344-350.

20. Elborn JS, Flume PA, Cohen F, Loutit J, VanDevanter DR. Safety and efficacy of prolonged levofloxacin inhalation solution (APT-1026) treatment for cystic fibrosis and chronic Pseudomonas aeruginosa airway infection. J Cyst Fibros 2016; 15: 634-640.

21. Mogayzel PJ, Jr., Naureckas ET, Robinson KA, Brady C, Guill M, Lahiri T, Lubsch L, Matsui J, Oermann CM, Ratjen F, Rosenfeld M, Simon RH, Hazle L, Sabadosa K, Marshall BC, Cystic Fibrosis Foundation Pulmonary Clinical Practice Guidelines C. Cystic Fibrosis Foundation pulmonary guideline. pharmacologic approaches to prevention and eradication of initial Pseudomonas aeruginosa infection. Ann Am Thorac Soc 2014; 11: 1640-1650.

22. Heijerman H, Westerman E, Conway S, Touw D, Doring G, consensus working g. Inhaled medication and inhalation devices for lung disease in patients with cystic fibrosis: A European consensus. J Cyst Fibros 2009; 8: 295-315.

23. Flume PA, Clancy JP, Retsch-Bogart GZ, Tullis DE, Bresnik M, Derchak PA, Lewis SA, Ramsey BW. Continuous alternating inhaled antibiotics for chronic pseudomonal infection in cystic fibrosis. $J$ Cyst Fibros 2016; 15: 809-815.

24. Abou Alaiwa MH, Launspach JL, Grogan B, Carter S, Zabner J, Stoltz DA, Singh PK, McKone EF, Welsh MJ. Ivacaftor-induced sweat chloride reductions correlate with increases in airway surface liquid $\mathrm{pH}$ in cystic fibrosis. JCl Insight 2018; 3.

25. Hisert KB, Heltshe SL, Pope C, Jorth P, Wu X, Edwards RM, Radey M, Accurso FJ, Wolter DJ, Cooke G, Adam RJ, Carter S, Grogan B, Launspach JL, Donnelly SC, Gallagher CG, Bruce JE, Stoltz DA, Welsh MJ, Hoffman LR, McKone EF, Singh PK. Restoring Cystic Fibrosis Transmembrane Conductance Regulator Function Reduces Airway Bacteria and Inflammation in People with Cystic Fibrosis and Chronic Lung Infections. Am J Respir Crit Care Med 2017; 195: 1617-1628.

26. Rowe SM, Heltshe SL, Gonska T, Donaldson SH, Borowitz D, Gelfond D, Sagel SD, Khan U, MayerHamblett N, Van Dalfsen JM, Joseloff E, Ramsey BW, Network GlotCFFTD. Clinical mechanism of the cystic fibrosis transmembrane conductance regulator potentiator ivacaftor in G551D-mediated cystic fibrosis. Am J Respir Crit Care Med 2014; 190: 175-184.

27. Harris JK, Wagner BD, Zemanick ET, Robertson CE, Stevens MJ, Heltshe SL, Rowe SM, Sagel SD, Network GlotCFFTD. Changes in Airway Microbiome and Inflammation with Ivacaftor Treatment in Patients with Cystic Fibrosis and the G551D Mutation. Ann Am Thorac Soc 2019.

28. Middleton PG, Mall MA, Drevinek P, Lands LC, McKone EF, Polineni D, Ramsey BW, Taylor-Cousar JL, Tullis E, Vermeulen F, Marigowda G, McKee CM, Moskowitz SM, Nair N, Savage J, Simard C, Tian S, Waltz D, Xuan F, Rowe SM, Jain R, Group VXS. Elexacaftor-Tezacaftor-Ivacaftor for Cystic Fibrosis with a Single Phe508del Allele. N Engl J Med 2019; 381: 1809-1819.

29. Heijerman HGM, McKone EF, Downey DG, Van Braeckel E, Rowe SM, Tullis E, Mall MA, Welter JJ, Ramsey BW, McKee CM, Marigowda G, Moskowitz SM, Waltz D, Sosnay PR, Simard C, Ahluwalia N, Xuan F, Zhang Y, Taylor-Cousar JL, McCoy KS, Group VXT. Efficacy and safety of the elexacaftor plus 
tezacaftor plus ivacaftor combination regimen in people with cystic fibrosis homozygous for the F508del mutation: a double-blind, randomised, phase 3 trial. Lancet 2019; 394: 1940-1948.

30. Heltshe SL, Mayer-Hamblett N, Burns JL, Khan U, Baines A, Ramsey BW, Rowe SM, Network GlotCFFTD. Pseudomonas aeruginosa in cystic fibrosis patients with G551D-CFTR treated with ivacaftor. Clin Infect Dis 2015; 60: 703-712.

31. Gifford AH, Mayer-Hamblett N, Pearson K, Nichols DP. Answering the call to address cystic fibrosis treatment burden in the era of highly effective CFTR modulator therapy. J Cyst Fibros 2019.

32. Rayment JH, Stanojevic S, Davis SD, Retsch-Bogart G, Ratjen F. Lung clearance index to monitor treatment response in pulmonary exacerbations in preschool children with cystic fibrosis. Thorax 2018; 73: 451-458.

33. Sonneveld N, Stanojevic S, Amin R, Aurora P, Davies J, Elborn JS, Horsley A, Latzin P, O'Neill K, Robinson $P$, Scrase E, Selvadurai $H$, Subbarao $P$, Welsh L, Yammine S, Ratjen F. Lung clearance index in cystic fibrosis subjects treated for pulmonary exacerbations. Eur Respir J 2015; 46: 1055-1064.

34. Gold LS, Patrick DL, Hansen RN, Goss CH, Kessler L. Correspondence between lung function and symptom measures from the Cystic Fibrosis Respiratory Symptom Diary-Chronic Respiratory Infection Symptom Score (CFRSD-CRISS). J Cyst Fibros 2019; 18: 886-893.

35. Perrem L, Ratjen F. Anti-inflammatories and mucociliary clearance therapies in the age of CFTR modulators. Pediatr Pulmonol 2019; 54 Suppl 3: S46-S55.

36. Registry CFFP. Annual data report to the Center Directors, Bethesda Maryland, 2019: Cystic Fibrosis Foundation.; 2018.

37. Konstan MW. Treatment of airway inflammation in cystic fibrosis. Curr Opin Pulm Med 1996; 2: 452456.

38. Konstan MW, Byard PJ, Hoppel CL, Davis PB. Effect of high-dose ibuprofen in patients with cystic fibrosis. N Engl J Med 1995; 332: 848-854.

39. Lands LC, Milner R, Cantin AM, Manson D, Corey M. High-dose ibuprofen in cystic fibrosis: Canadian safety and effectiveness trial. J Pediatr 2007; 151: 249-254.

40. Konstan MW, VanDevanter DR, Sawicki GS, Pasta DJ, Foreman AJ, Neiman EA, Morgan WJ. Association of High-Dose Ibuprofen Use, Lung Function Decline, and Long-Term Survival in Children with Cystic Fibrosis. Ann Am Thorac Soc 2018; 15: 485-493.

41. Torphy TJ, Allen J, Cantin AM, Konstan MW, Accurso FJ, Joseloff E, Ratjen FA, Chmiel JF, Antiinflammatory Therapy Working G. Considerations for the Conduct of Clinical Trials with Antiinflammatory Agents in Cystic Fibrosis. A Cystic Fibrosis Foundation Workshop Report. Ann Am Thorac Soc 2015; 12: 1398-1406.

42. Sagel SD, Chmiel JF, Konstan MW. Sputum biomarkers of inflammation in cystic fibrosis lung disease. Proc Am Thorac Soc 2007; 4: 406-417.

43. Ordonez CL, Henig NR, Mayer-Hamblett N, Accurso FJ, Burns JL, Chmiel JF, Daines CL, Gibson RL, McNamara S, Retsch-Bogart GZ, Zeitlin PL, Aitken ML. Inflammatory and microbiologic markers in induced sputum after intravenous antibiotics in cystic fibrosis. Am J Respir Crit Care Med 2003; 168: 1471-1475.

44. Mayer-Hamblett N, Aitken ML, Accurso FJ, Kronmal RA, Konstan MW, Burns JL, Sagel SD, Ramsey BW. Association between pulmonary function and sputum biomarkers in cystic fibrosis. Am J Respir Crit Care Med 2007; 175: 822-828.

45. Sagel SD, Wagner BD, Anthony MM, Emmett P, Zemanick ET. Sputum biomarkers of inflammation and lung function decline in children with cystic fibrosis. Am J Respir Crit Care Med 2012; 186: 857865.

46. Sly PD, Gangell CL, Chen L, Ware RS, Ranganathan S, Mott LS, Murray CP, Stick SM, Investigators AC. Risk factors for bronchiectasis in children with cystic fibrosis. N Engl J Med 2013; 368: 1963-1970. 
47. VanDevanter DR, Konstan MW. Outcome measures for clinical trials assessing treatment of cystic fibrosis lung disease. Clin Investig (Lond) 2012; 2: 163-175.

48. Konstan MW, Wagener JS, Yegin A, Millar SJ, Pasta DJ, VanDevanter DR. Design and powering of cystic fibrosis clinical trials using rate of FEV(1) decline as an efficacy endpoint. J Cyst Fibros 2010; 9: 332-338.

49. Chmiel JF, Konstan MW, Accurso FJ, Lymp J, Mayer-Hamblett N, VanDevanter DR, Rose LM, Ramsey BW, Assessment of Induced Sputum in Cystic Fibrosis Study G. Use of ibuprofen to assess inflammatory biomarkers in induced sputum: Implications for clinical trials in cystic fibrosis. J Cyst Fibros 2015; 14: 720-726.

50. Ramsey BW, Davies J, McElvaney NG, Tullis E, Bell SC, Drevinek P, Griese M, McKone EF, Wainwright CE, Konstan MW, Moss R, Ratjen F, Sermet-Gaudelus I, Rowe SM, Dong Q, Rodriguez S, Yen K, Ordonez C, Elborn JS, Group VXS. A CFTR potentiator in patients with cystic fibrosis and the G551D mutation. N Engl J Med 2011; 365: 1663-1672.

51. US Code of Federal Regulations. 21CFR 5051-52.

52. Pediatric Research Equity Act of 2007 Title IV FDA Amendments Act 2007; 2007.

53. US Best Pharmaceuticals for Children Act (BPCA). 2007.

54. Rose K, Spigarelli MG. Cystic Fibrosis Treatment: A Paradigm for New Pediatric Medicines, Globalization of Drug Development and the Role of the European Medicines Agency. Children (Basel) 2015; 2: 108-130.

55. Group T. Study on the economic impact of the Paediatric Regulation, including its rewards and incentives. 2016. Available from: https://ec.europa.eu/health/sites/health/files/files/paediatrics/docs/paediatrics 10 years econo mic study.pdf.

56. Davies JC, Cunningham S, Harris WT, Lapey A, Regelmann WE, Sawicki GS, Southern KW, Robertson S, Green Y, Cooke J, Rosenfeld M, Group KS. Safety, pharmacokinetics, and pharmacodynamics of ivacaftor in patients aged 2-5 years with cystic fibrosis and a CFTR gating mutation (KIWI): an openlabel, single-arm study. Lancet Respir Med 2016; 4: 107-115.

57. Rosenfeld M, Wainwright CE, Higgins M, Wang LT, McKee C, Campbell D, Tian S, Schneider J, Cunningham S, Davies JC, group As. Ivacaftor treatment of cystic fibrosis in children aged 12 to $<24$ months and with a CFTR gating mutation (ARRIVAL): a phase 3 single-arm study. Lancet Respir Med 2018; 6: 545-553.

58. Saunders C, Jensen R, Robinson PD, Stanojevic S, Klingel M, Short C, Davies JC, Ratjen F. Integrating the multiple breath washout test into international multicentre trials. J Cyst Fibros 2019.

59. Ratjen F, Hug C, Marigowda G, Tian S, Huang X, Stanojevic S, Milla CE, Robinson PD, Waltz D, Davies $J C$, group VXi. Efficacy and safety of lumacaftor and ivacaftor in patients aged 6-11 years with cystic fibrosis homozygous for F508del-CFTR: a randomised, placebo-controlled phase 3 trial. Lancet Respir Med 2017; 5: 557-567. 
Figure 1 - CF Therapeutics Drug Pipeline. Reproduced with permission of the US Cystic Fibrosis Foundation, Bethesda, Maryland. Copyright (c) March 18, 2020 by the US Cystic Fibrosis Foundation. The pipeline includes any new therapies that are either being funded by the Cystic Fibrosis Foundation (\$US2 million or more in support) or being tested by clinical trials in the Cystic Fibrosis Foundation Therapeutics Development Network. Therapies at the end of phase 3 completion or indicated as available to patients represent status within the United States, which may notably differ from global access and availability.

\section{DRUG DEVELOPMENT PIPELINE}

\begin{tabular}{|c|c|c|c|c|c|}
\hline 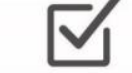 & $\begin{array}{l}\text { THERAPIES } \\
\text { AVAILABLE }\end{array}$ & $\begin{array}{l}\text { THERAPIES } \\
\text { AVAILABLE }\end{array}$ & 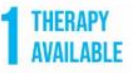 & $\begin{array}{l}5 \text { THERAPIES } \\
\text { AVAILABLE }\end{array}$ & $\begin{array}{l}\text { THERAPIES } \\
\text { AVAILABLE }\end{array}$ \\
\hline $\begin{array}{r}\text { AVAILABLE TO } \\
\text { PATIENTS }\end{array}$ & $\begin{array}{l}\text { - Elexacaftor + tezacaftor + } \\
\text { ivacaftor (Trikafta }{ }^{\mathrm{TM}} \text { ) } \\
\text { - Ivacaftor (Kalydeco }(\mathrm{B}) \\
\text { - Lumacaftor + ivacaftor } \\
\text { (Orkambi }(\text { ) } \\
\text { - Tezacaftor + ivacaftor (SymdekoTM) }\end{array}$ & $\begin{array}{l}=\text { Dornase alfa } \\
\text { (Pulmozyme }{ }^{\circledR)} \\
=\text { Hypertonic } \\
\text { saline }\end{array}$ & $\begin{array}{l}\text { High dose } \\
\text { ibuprofen } \\
\text { for CF }\end{array}$ & 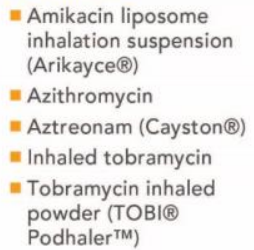 & $\begin{array}{l}\text { - AquADEKs } \\
\text { - Pancrelipase } \\
\text { enzyme } \\
\text { products } \\
\text { - } \text { RELiZORB } \circledast\end{array}$ \\
\hline
\end{tabular}

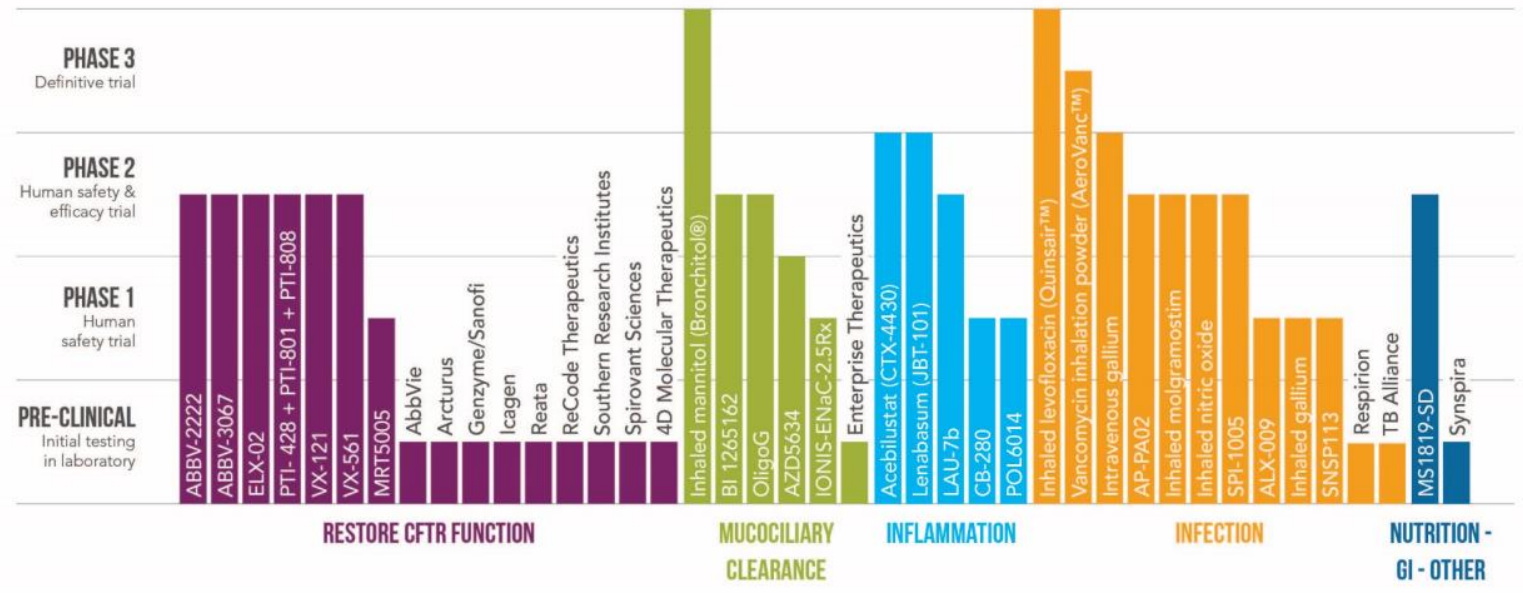

Programs on this pipeline meet at least one of these criteria: a) funding from the Foundation of at least $\$ 2$ million; b) funding from the Foundation that includes payments dependent on the drug reaching clinical trials; c) clinical trials supported by the Therapeutics Development Network (TDN). 
Table 2 - Comparison of Select Regulator Preferences Based on Precedent-Setting Late Phase Development Programs and Key Considerations to Ensure Successful Future Development Programs as CFTR Modulator Therapy is More Broadly Transitioned into SOC

\begin{tabular}{|c|c|c|c|c|c|c|c|}
\hline \multicolumn{7}{|c|}{ Past and Current Regulatory Pathways } & \multirow{3}{*}{$\begin{array}{l}\text { Future Pathways } \\
\text { Key Considerations to Ensure Success for } \\
\text { Future Global Development Programs } \\
\text { within the Context of Standard of Care } \\
\text { Modulator Therapy }\end{array}$} \\
\hline & \multicolumn{4}{|c|}{ Preferred Pivotal Trial Design ${ }^{1}$} & \multicolumn{2}{|c|}{ Label Expansion Approach } & \\
\hline & $\begin{array}{l}\text { Comparator } \\
\text { \& Hypothesis }\end{array}$ & Blinding & Primary Endpoint & Duration & $\begin{array}{c}\text { Pediatric } \\
\text { Development }\end{array}$ & $\begin{array}{c}\text { Novel Approval } \\
\text { mechanisms }\end{array}$ & \\
\hline \multicolumn{8}{|c|}{ CFTR Modulator Therapies } \\
\hline EMA & $\begin{array}{l}\text { Placebo- } \\
\text { controlled; } \\
\text { Superiority } \\
\text { Hypothesis }\end{array}$ & Blinded & $\begin{array}{l}\text { Difference in } \\
\text { ppFEV }_{1} \text { change }\end{array}$ & 6 months & $\begin{array}{l}\text { Placebo controlled } \\
\text { study required; } \\
\text { Difference in } \mathrm{LCl} \\
\text { change from } \\
\text { baseline primary } \\
\text { efficacy endpoint }\end{array}$ & No current precedent & \multirow{2}{*}{$\begin{array}{l}\text { - Feasibility and, if applicable, duration of } \\
\text { future placebo-controlled trials once SOC } \\
\text { modulator therapy is established must be } \\
\text { determined and accepted by regulators. } \\
\text { Design will be based on contemporary and } \\
\text { ongoing evidence both from survey efforts } \\
\text { to assess the willingness of individuals with } \\
\text { CF to withdraw from modulator therapy } \\
\text { and from safety data from ongoing trials } \\
\text { including periods of withdrawal of } \\
\text { modulator therapy. } \\
\text { - Open-label, prescription-based active- } \\
\text { comparator trials may be a necessary } \\
\text { component for establishing the efficacy of } \\
\text { new modulators once SOC modulator } \\
\text { therapy is established. Non-inferiority } \\
\text { margins in this context must be carefully } \\
\text { considered in relation to total clinical } \\
\text { benefit rather than simply comparability } \\
\text { to the active comparator. } \\
\text { - Use of historical controls from reliable data } \\
\text { sources may become a necessary } \\
\text { augmentation to future development plans } \\
\text { to bolster efficacy data in the absence of } \\
\text { longer-term placebo-controlled trials. } \\
\text { - Sufficiency of a robust ppFEV } 1 \text { response } \\
\text { supported by clear MOA will be a necessary }\end{array}$} \\
\hline FDA & $\begin{array}{l}\text { Placebo- } \\
\text { controlled; } \\
\text { Superiority } \\
\text { Hypothesis }\end{array}$ & Blinded & $\begin{array}{l}\text { Difference in } \\
\text { ppFEV }_{1} \text { change from } \\
\text { baseline } \\
\text { (insufficient if } \\
\text { lacking a robust } \\
\text { response, which } \\
\text { may lead to request } \\
\text { for PEx efficacy } \\
\text { endpoint) }\end{array}$ & $\begin{array}{l}28 \text { days to } 6 \\
\text { months }\end{array}$ & $\begin{array}{l}\text { Safety but not } \\
\text { efficacy required } \\
\text { for pediatric } \\
\text { approval }\end{array}$ & $\begin{array}{l}\text { Approval for rare } \\
\text { mutations based on in } \\
\text { vitro data contingent } \\
\text { on prior regulatory } \\
\text { approval for other } \\
\text { populations for which } \\
\text { clear efficacy and } \\
\text { safety demonstrated }\end{array}$ & \\
\hline
\end{tabular}




\begin{tabular}{|c|c|c|c|c|c|c|c|}
\hline & & & & & & & $\begin{array}{l}\text { path to fulfill efficacy criteria as currently } \\
\text { defined PEx endpoints will be difficult to } \\
\text { assess in populations receiving CFTR } \\
\text { modulator therapy associated with } \\
\text { substantial clinical benefit due to lower } \\
\text { event rates and resulting increased sample } \\
\text { size requirements. } \\
\text { - A streamlined pathway for label expansion } \\
\text { for rare mutations including the use of in } \\
\text { vitro data will be essential for ensuring } \\
\text { access for all who will benefit. }\end{array}$ \\
\hline \multicolumn{8}{|c|}{ Anti-Infective Therapies for Chronic Airway Infection } \\
\hline EMA & $\begin{array}{l}\text { Standard of } \\
\text { Care Active- } \\
\text { Comparator; } \\
\text { Non- } \\
\text { inferiority } \\
\text { hypothesis }\end{array}$ & $\begin{array}{l}\text { Open } \\
\text { Label }\end{array}$ & $\begin{array}{l}\text { Difference in } \\
\text { ppFEV }_{1} \text { change from } \\
\text { baseline }\end{array}$ & 6 months & $\begin{array}{l}\text { PIP required } \\
\text { including } \\
\text { establishment of } \\
\text { efficacy in } \\
\text { pediatrics }\end{array}$ & NA & \multirow{2}{*}{$\begin{array}{l}\text { - Increased efforts to establish meaningful } \\
\text { non-inferiority margins using } \\
\text { contemporary data and decreasing the } \\
\text { risk of bio-creep (ineffectiveness of the } \\
\text { SOC active comparator over time) will be } \\
\text { essential for broader acceptance of active- } \\
\text { comparator designs across global } \\
\text { regulatory agencies. } \\
\text { - Monitoring for a reduction in the } \\
\text { prevalence of chronic anti-infective use } \\
\text { across the growing population on CFTR } \\
\text { modulators will be important to evaluate } \\
\text { the feasibility of placebo-controlled trials } \\
\text { across the globe. } \\
\text { - Acceptance of short-term placebo- } \\
\text { controlled pivotal trials (approx. } 1 \text { month) } \\
\text { demonstrating robust efficacy and MOA } \\
\text { represents an essential opportunity to } \\
\text { advance new chronic anti-infectives in } \\
\text { populations unable to withhold chronic } \\
\text { inhaled antibiotics for longer durations for } \\
\text { a placebo-control. } \\
\text { - Sufficiency of a robust clinically } \\
\text { meaningful ppFEV }{ }_{1} \text { response supported by } \\
\text { clear MOA may be a necessary path to }\end{array}$} \\
\hline FDA & $\begin{array}{l}\text { Placebo- } \\
\text { controlled; } \\
\text { Superiority } \\
\text { Hypothesis }\end{array}$ & Blinded & $\begin{array}{l}\text { Time to PEx or need } \\
\text { for antibiotics, } \\
\text { Difference in } \\
\text { ppFEV }_{1} \text { change from } \\
\text { baseline alone not } \\
\text { generally sufficient }\end{array}$ & $\begin{array}{l}\text { 3-6 months } \\
\text { (ppFEV } 1 \\
\text { change } \\
\text { endpoint } \\
\text { may be } \\
\text { measured } \\
\text { earlier) }\end{array}$ & $\begin{array}{l}\text { Safety but not } \\
\text { efficacy data } \\
\text { required for } \\
\text { pediatric approval }\end{array}$ & NA & \\
\hline
\end{tabular}




\begin{tabular}{|c|c|c|c|c|c|c|c|}
\hline & & & & & & & $\begin{array}{l}\text { fulfill efficacy criteria as currently defined } \\
\text { PEx endpoints will be difficult to assess in } \\
\text { populations receiving CFTR modulator } \\
\text { therapy associated with substantial } \\
\text { clinical benefit due to lower event rates } \\
\text { and resulting increased sample size } \\
\text { requirements. }\end{array}$ \\
\hline \multicolumn{8}{|c|}{ Anti-Inflammatory Therapies ${ }^{2}$} \\
\hline EMA & $\begin{array}{l}\text { Placebo- } \\
\text { controlled; } \\
\text { Superiority } \\
\text { Hypothesis }\end{array}$ & Blinded & $\begin{array}{l}\text { PEx rate (PEx using } \\
\text { a standardized } \\
\text { definition) }\end{array}$ & $\begin{array}{l}6 \text { months-1 } \\
\text { year }\end{array}$ & Unknown & NA & \multirow{2}{*}{$\begin{array}{l}\text { - A critical understanding of the changing } \\
\text { symptomatology of PEx in the presence of } \\
\text { CFTR modulators will be necessary to } \\
\text { define relevant and clinically meaningful } \\
\text { respiratory events coinciding with clinical } \\
\text { worsening to serve as sensitive endpoints } \\
\text { for these trials, as currently defined PEx } \\
\text { endpoints may be diminishing in } \\
\text { populations receiving CFTR modulator } \\
\text { therapy associated with substantial } \\
\text { clinical benefit (resulting in unfeasible } \\
\text { sample size requirements for trials using } \\
\text { PEx as an endpoint). }\end{array}$} \\
\hline FDA & $\begin{array}{l}\text { Placebo- } \\
\text { controlled; } \\
\text { Superiority } \\
\text { Hypothesis }\end{array}$ & Blinded & $\begin{array}{l}\text { PEx rate (PEx using } \\
\text { a standardized } \\
\text { definition) }\end{array}$ & $\begin{array}{l}6 \text { months- } 1 \\
\text { year }\end{array}$ & Unknown & NA & \\
\hline
\end{tabular}

${ }^{1}$ Pivotal trials for initial indication or CF patient population.

${ }^{2}$ No regulatory approved anti-inflammatory therapies, extrapolated based on current phase $2 \mathrm{~b}$ trial designs.

FDA: Food and Drug Administration, EMA: European Medical Agency; NA, not applicable; ppFEV $\mathrm{F}_{1}$, percent predicted forced expiratory volume in $1 \mathrm{sec}$; Abx, antibiotic;; LCl, lung clearance index; MOA, mechanism of action; SOC, standard of care; PEx, pulmonary exacerbation; PIP, pediatric investigation plan 
Table 3 - Example of a Future Study Design Package for a New CFTR Modulator to Address Global Requirements for Efficacy and Safety

\begin{tabular}{|c|c|c|c|c|c|}
\hline \multicolumn{5}{|c|}{ Example Studies Contributing to a Comprehensive Package } & \multirow[b]{2}{*}{$\begin{array}{c}\text { Combined Attributes from } \\
\text { All Studies }\end{array}$} \\
\hline Study Design Attributes & $\begin{array}{l}\text { Short Placebo- } \\
\text { Controlled } \\
\text { Trial } \\
\text { (2 weeks - } \\
\text { <1 mos.) }\end{array}$ & $\begin{array}{c}\text { Open-Label, } \\
\text { Prescription Reliant } \\
\text { Active Comparator }^{1} \\
\text { Trial (3- } 6 \text { mos.) }\end{array}$ & $\begin{array}{c}\text { Open-label } \\
\text { Active Arm } \\
\text { Safety Study }{ }^{2} \\
\text { (1 year) }\end{array}$ & $\begin{array}{c}\text { Retrospective Study: } \\
\text { Historical Control vs. } \\
\text { Pooled Active Arms across } \\
\text { Studies } \\
\text { (6 mos.-1 year) }\end{array}$ & \\
\hline Comparator Group & V & $\sqrt{ }$ & - & $\checkmark$ & $\sqrt{ }$ \\
\hline Blinded Treatment Arms & $\sqrt{ }$ & - & - & - & $\sqrt{ }$ \\
\hline Superiority Hypothesis & $\sqrt{ }$ & - & - & $\sqrt{ }$ & v \\
\hline Non-Inferiority Hypothesis & - & $\sqrt{ }$ & - & - & $\sqrt{ }$ \\
\hline Clinical Efficacy Evaluation & $\checkmark$ & $\sqrt{ }$ & - & $\sqrt{ }$ & $\sqrt{ }$ \\
\hline Short term & V & V & - & - & v \\
\hline Long term & - & $?^{1}$ & - & $\checkmark$ & $\checkmark$ \\
\hline $\mathrm{FEV}_{1}$ & v & $v$ & - & v & v \\
\hline PEx & - & - & - & $V^{3}$ & $\checkmark$ \\
\hline Safety Evaluation & V & $v$ & v & - & v \\
\hline Short term & v & $v$ & $v$ & - & v \\
\hline Long term & - & $?^{1}$ & v & - & v \\
\hline
\end{tabular}

$\mathrm{FEV}_{1}=$ forced expiratory volume in one second, $\mathrm{PEx}=$ pulmonary exacerbation 
${ }^{1}$ Duration of the active-comparator dependent on feasibility of reliance on prescription-based therapy, as well as a duration that mitigates risk of confounding due to access by both treatment arms to study drug. Duration of the trial will drive ability of the study to address long term efficacy and safety.

${ }^{2}$ Open label safety study would be a follow-on study for participants in the placebo and active-controlled trial, in addition to a free-standing study to enroll additional participants and increase the size of the safety database.

${ }^{3}$ Assessment of a pulmonary exacerbation-related endpoint dependent on availability of a consistent definition across databases. 
Table 4 - Overview of Regional Pediatric Development Regulations

\begin{tabular}{l|l|l|l|l|l|l}
\hline Agency & $\begin{array}{c}\text { Pharmacokinetic } \\
\text { Testing for } \\
\text { Dosing }\end{array}$ & $\begin{array}{c}\text { Requirement } \\
\text { for an } \\
\text { Appropriate } \\
\text { Pediatric } \\
\text { Formulation }\end{array}$ & $\begin{array}{c}\text { Safety } \\
\text { Endpoints }\end{array}$ & $\begin{array}{c}\text { Efficacy } \\
\text { Endpoints }\end{array}$ & $\begin{array}{c}\text { Extrapolation } \\
\text { Plan }\end{array}$ \\
\hline EMA & Yes & Yes & Yes & $\begin{array}{l}\text { Usually } \\
\text { required }\end{array}$ & $\begin{array}{l}\text { Not routinely } \\
\text { acceptable }\end{array}$ & $\begin{array}{l}\text { End of } \\
\text { phase 1, } \\
\text { amended } \\
\text { as needed }\end{array}$ \\
\hline FDA & Yes & Yes & Yes & $\begin{array}{l}\text { Not required, if } \\
\text { extrapolation } \\
\text { supports } \\
\text { efficacy }\end{array}$ & Yes & End of \\
phase 2
\end{tabular}

${ }^{1}$ To the FDA within 60 days of the end-of-phase 2 meeting or no later than 210 days before planned new drug application (NDA) submission, but not mandatory for orphan drug development programs.

FDA=Food and Drug Administration, EMA=European Medical Agency 